\title{
Spray drift characteristics test of unmanned aerial vehicle spray unit under wind tunnel conditions
}

\author{
Changling Wang ${ }^{1,2}$, Aijun Zeng ${ }^{1,3}$, Xiongkui He ${ }^{1,3 *}$, Jianli Song ${ }^{1,3}$, Andreas Herbst ${ }^{4}$, Wanlin $\mathrm{Gao}^{2}$ \\ (1. Centre for Chemicals Application Technology, China Agricultural University, Beijing 100193, China; \\ 2. College of Information and Electrical Engineering, China Agricultural University, Beijing 100083, China; \\ 3. College of Science, China Agricultural University, Beijing 100193, China; \\ 4. Institute for Chemical Application Technology of JKI, Messeweg 11/12 D-38104 Braunschweig, Germany)
}

\begin{abstract}
Since the 2010s, unmanned aerial vehicle (UAV) sprayer was applied more and more widely for low-volume aerial pesticides spraying operations in China. However, droplets from the UAV sprayer have a higher drift risk due to more fine droplets sprayed and a higher flight height than ground sprayers. Study on UAV spray drift has been a new hot spot within the field of pesticide application technology. Most of previous studies used direct field methods for spray drift, but the meteorological conditions in field were unstable and uncontrollable, and drift research under an actual operation state in wind tunnel has not been reported. Therefore, 25 treatments of wind tunnel measurements and droplets spectrum tests of 10 models of nozzles were conducted to explore the influence factor on spray drift characteristics of UAV chemicals application in this study. A spray unit with a rotor of UAV was innovatively installed in wind tunnel, and the airstream from the wind tunnel was regarded as the relative moving natural wind to simulate the flight status. The airborne and the sediment spray drift was measured to study the effects of the nozzle type and size (flat fan, hollow cone and air-inclusion nozzles), flight speed, adjuvant (DRS-60, Y-20079, MF and G-611) and meteorological parameters $\left(20^{\circ} \mathrm{C} \& 40 \%, 20^{\circ} \mathrm{C} \& 80 \%, 30^{\circ} \mathrm{C} \& 40 \%\right.$ and $\left.30{ }^{\circ} \mathrm{C} \& 60 \%\right)$. The drift potential $(D P)$ and the drift potential reduction percentage $(D P R P)$ in vertical and horizontal directions were obtained for each test. Both nozzle type and size had an impact on the spray drift potential obviously by affecting the droplet size and the ratio of fine droplets, and the regression linear models between $D P R P_{V} / D P R P_{H}$ and $D V_{50}, V_{75}$ were established $\left(R^{2}=0.934 / 0.925\right)$. Flight speed also had a significant effect on the spray drift characteristics, and reducing the flight speed could increase the $D P$ effectively. Adding spray adjuvants could affect the $D P$ under experimental meteorological parameters, and the anti-drift performance ranked in the order of DRS-60>MF>Y-20079>G-611. Recommendations were proposed in order to reduce the spray drift for UAV sprayer's operation. These findings can contribute to provide guidelines and technical support for the wind tunnel spray drift tests of UAV and the field operation regulation of unmanned aerial PPP application.
\end{abstract}

Keywords: unmanned aerial vehicle (UAV) sprayer, wind tunnel, spray drift potential, nozzle, adjuvant

DOI: $10.25165 /$ j.ijabe.20201303.5716

Citation: Wang C L, Zeng A J, He X K, Song J L, Herbst A, et al. Spray drift characteristics test of unmanned aerial vehicle spray unit under wind tunnel conditions. Int J Agric \& Biol Eng, 2020; 13(3): 13-21.

\section{Introduction}

Since the 2010s, the application of unmanned aerial vehicle (UAV) for low-volume aerial pesticides (also known as plant protection products, PPP) spraying was more and more wide in China because of its superior performances ${ }^{[1,2]}$, such as the good flexibility for plant protection works in those fields where ground machines can't drive, and the high working efficiency to cope with unexpected disasters, reducing the hazards to humans and the

\section{Received date: 2020-02-05 Accepted date: 2020-04-13}

Biographies: Changling Wang, PhD, Postdoctor, research interests: aerial pesticide application technology, Email: wc11991@cau.edu.cn; Aijun Zeng, $\mathrm{PhD}$, Associated professor, research interests: pesticide application technology, Email: aijunz@cau.edu.cn; Jianli Song, PhD, Associated Professor, research interests: pesticide application technology, Email: songjianli170@163.com; Andreas Herbst, $\mathrm{PhD}$, Engineering Scientist, research interests: pesticide application technology, Email: andreas.herbst@jki.bund.de; Wanlin Gao, PhD, Professor, research interests: agricultural informationization and application specific chip, Email: wanlin_cau@163.com.

*Corresponding author: Xiongkui $\mathrm{He}, \mathrm{PhD}$, Professor, research focuses on pesticide application technology. Centre for Chemicals Application Technology (CCAT), China Agricultural University, No.2, Yuanmingyuan Xilu, Haidian District, Beijing 100193, China. Tel: +86-10-62731446, Email: xiongkui@cau.edu.cn. environmental pollution during the spraying process ${ }^{[3-6]}$. Up to the end of 2018, the marketing holdings of UAV sprayers were approximately 31.5 thousand and the annual sales went up to 10 thousand, and its annual working area reached 17.3 million $\mathrm{hm}^{2}$ all over the country ${ }^{[7]}$. However, droplets sprayed from the UAV sprayers have a higher risk of spray drift due to the low volume (LV) or ultra-low volume (ULV) spray method with more fine droplets, together with a higher flight height than conventional ground sprayers and also the unreasonable choice of the flight parameters and meteorological conditions ${ }^{[8]}$, leading to the reduction of pesticides efficacy, the crop's phytotoxicity and the non-target environmental pollution, especially serious for the herbicides application ${ }^{[7]}$. Thus, study on spray drift of the UAV sprayer has been a new hot spot within the field of pesticide application technology not only in China, but also in the other countries in Asia ${ }^{[1,2,9]}$.

The testing method of spray drift mainly consists of the direct field test and the indirect evaluation test. The field test is to measure the actual spray drift outdoors in typical field conditions or over a defined surface including grass turf ${ }^{[10]}$ and considered as the most realistic drift measurement method. Wang et al. ${ }^{[11]}$ measured the airborne and sediment spray drift of 3 typical models of single-rotor UAVs and 6 types of adjuvants in wheat field. 
Wang J. et al. ${ }^{[12,13]}$ conducted the spray drift and deposition tests using a single-rotor UAV in a pineapple field at different heights and meteorological conditions. Herbst et al. ${ }^{[14]}$ compared the airborne and sediment drift of Lechler TR 80-0067 and IDK 120-015 nozzle equipped on 3 types of UAVs. On the other hand, the evaluation test includes wind tunnel test ${ }^{[15]}$, drift bench test ${ }^{[16,17]}$, and droplets spectrum test ${ }^{[18,19]}$, and the drift potential reduction rate is calculated by measuring the spray deposition rate or the droplet size distribution ratio for analysis ${ }^{[20-22]}$. Nuyttens et al. ${ }^{[23]}$ carried out wind tunnel measurements to measure airborne and fallout spray volumes for 10 different spray nozzles. Torrent et al. ${ }^{[24]}$ conducted the drift evaluation of hollow cone nozzles by comparing 3 indirect testing methods of spray drift and found the evaluated indirect methods could provide similar classification results.

At present, most of studies on UAV spray drift use the direct field test methods, but the meteorological conditions in field are very unstable and uncontrollable, which affects the repeatability and operability of the measurement greatly. And as an important feature of the UAV, the rotor's downwash airflow can help promote the droplets deposition during the operation, but the drift study under the effect of downwash airflow in wind tunnel has not been reported before. Therefore, wind tunnel and droplets spectrum measurements were used to explore the influence factors on spray drift characteristics of UAV chemicals application in this study. A UAV spray unit with a rotor was innovatively installed in wind tunnel to generate downwash airflow, and the airstream from the wind tunnel was regarded as the relative moving natural wind to simulate the actual operation status. The effects of the nozzle type, nozzle size, flight speed, adjuvant and meteorological parameter were tested under the combination of the downwash airflow and the external wind. Findings of this study are expected to provide guidelines for the wind tunnel spray drift tests of UAV sprayers and the field operation regulation of unmanned aerial PPP application.

\section{Materials and methods}

\subsection{Arrangement in the JKI wind tunnel}

Wind tunnel experiments were conducted at Institute for Application Techniques in Plant Protection, Julius-Kühn-Institut (JKI-AT), in Brauschweig, Germany from November to December in 2018. The JKI wind tunnel has been used in several studies $^{[25-27]}$. The tunnel's technical parameters were stable and could be continuously adjustable within limits. This wind tunnel has a re-circulating design with a working section of $2.5 \mathrm{~m}$ wide, $1.6 \mathrm{~m}$ high and $10.0 \mathrm{~m}$ long, and produces a uniform airstream with a working airflow speed range of $0.3-15.0 \mathrm{~m} / \mathrm{s}$. Environmental conditions in the wind tunnel can be set at the range of $10-30^{\circ} \mathrm{C}$ and $40 \%-80 \%$ relative humidity $(\mathrm{RH})$ and the pressure of the spraying system is up to $8.0 \mathrm{MPa}$.

In order to study spray droplets drift characteristics of unmanned rotorcraft under the flying state, one single spray unit of a quadrotor UAV '3WQFTX-10' (Anyang Quanfeng Aviation Plant Protection Technology Co. Ltd, China), consisted of a rotor, a motor and a spraying system, was mounted in the wind tunnel for the first time and presented in Figure 1. The rotor diameter is $76.2 \mathrm{~cm}$ and the working speed is from $2000 \mathrm{r} / \mathrm{min}$ (no load) to $2800 \mathrm{r} / \mathrm{min}$ (full load). It was originally planned to deploy a quadrotor sprayer in the wind tunnel directly (fuselage width with rotors is $2.13 \mathrm{~m}$ ), but the wind tunnel width was only $2.5 \mathrm{~m}$ and the rotor was rotating at a high speed $(>2000 \mathrm{r} / \mathrm{min})$ during tests.
Considering both the safety of test process and the accuracy of the results, the complete droplet cloud under the action of the non-destructive downwash airflow need to be collected as much as possible while maintaining a certain safe distance between the rotor and the side wall of the wind tunnel, so only a single spray unit was used to avoid the inaccuracy caused by sprayed droplets and rotor's airflow in the edge area.

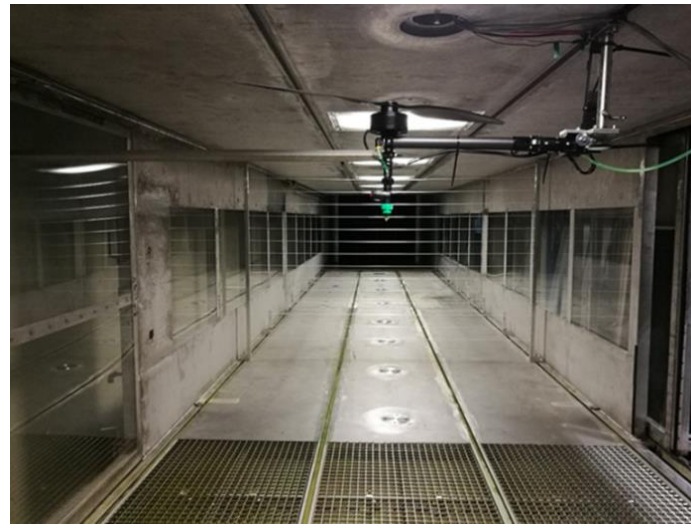

Figure 1 Spray unit of the quadrotor UAV fixed in the wind tunnel

The drift measurement arrangements were set according to the ISO 22856 standard $^{[15]}$. The nozzle of the spraying unit was fixed at the height of $1.0 \mathrm{~m}$. The spray drift was collected both in a plane perpendicular to the airflow at $3.0 \mathrm{~m}$ downwind from the nozzle position and another plane parallel to the ground at the height of $0.2 \mathrm{~m}$ by the $\varphi 1.98 \mathrm{~mm}$ PORTEX fine bore polythene tube (Smiths Medical International Ltd., UK). The experimental arrangements in the JKI wind tunnel are shown in Figure 2. Thirteen vertical sampling lines $(0.2-1.5 \mathrm{~m}$ in height) with $0.1 \mathrm{~m}$ spacing were placed to determine the vertical profile of the airborne spray drift while another 5 horizontal sampling lines were set at the downwind distance of $4.0 \mathrm{~m}, 5.0 \mathrm{~m}, 6.0 \mathrm{~m}, 7.0 \mathrm{~m}$ and $8.0 \mathrm{~m}$ to collect the sediment spray drift.

\subsection{Downwind drift measurements}

A type of water-soluble fluorescent tracer dye, Pyranine $120 \%$ (Simon \& Werner GmbH, Floersheim, Germany), was prepared at a concentration of $1.0 \mathrm{~g} / \mathrm{L}$ for wind tunnel drift tests. The original purpose of design of the wind tunnel was to simulate the airflow around the aircraft for aerodynamic experiments and the wind tunnel experiment is an indispensable part of the development of aircrafts $^{[28]}$. Apart from aerospace science, wind tunnel experiments have been widely applied within the fields of vehicle design, architecture, wind energy utilization and chemicals spray, etc. Under the condition of calm wind, airflow's acts on droplets cloud during flying are mainly caused by the relative movement between UAV sprayer and the outside air except for the rotor's downwash wind. In this study, it was designed that the airstream from the wind tunnel was regarded as the relative moving natural wind. Therefore, the tracer solution was sprayed at a pressure of $0.3 \mathrm{MPa}$ under two wind tunnel speeds $(2.0 \mathrm{~m} / \mathrm{s}$ or $5.0 \mathrm{~m} / \mathrm{s})$ and the rotor worked at a speed of $2300 \mathrm{r} / \mathrm{min}$ in drift potential measurements to simulate the status of UAV sprayer's operation in field.

Nozzle type and size, flight speed, adjuvant and meteorological parameters were focused to explore the influence factor on spray drift characteristics of UAV under the rotor's downwash airflow and the external wind. A total of 25 trials were carried out with 3 replicates in the JKI wind tunnel and the trial settings of environmental condition and spray liquid are shown in Table 1. 


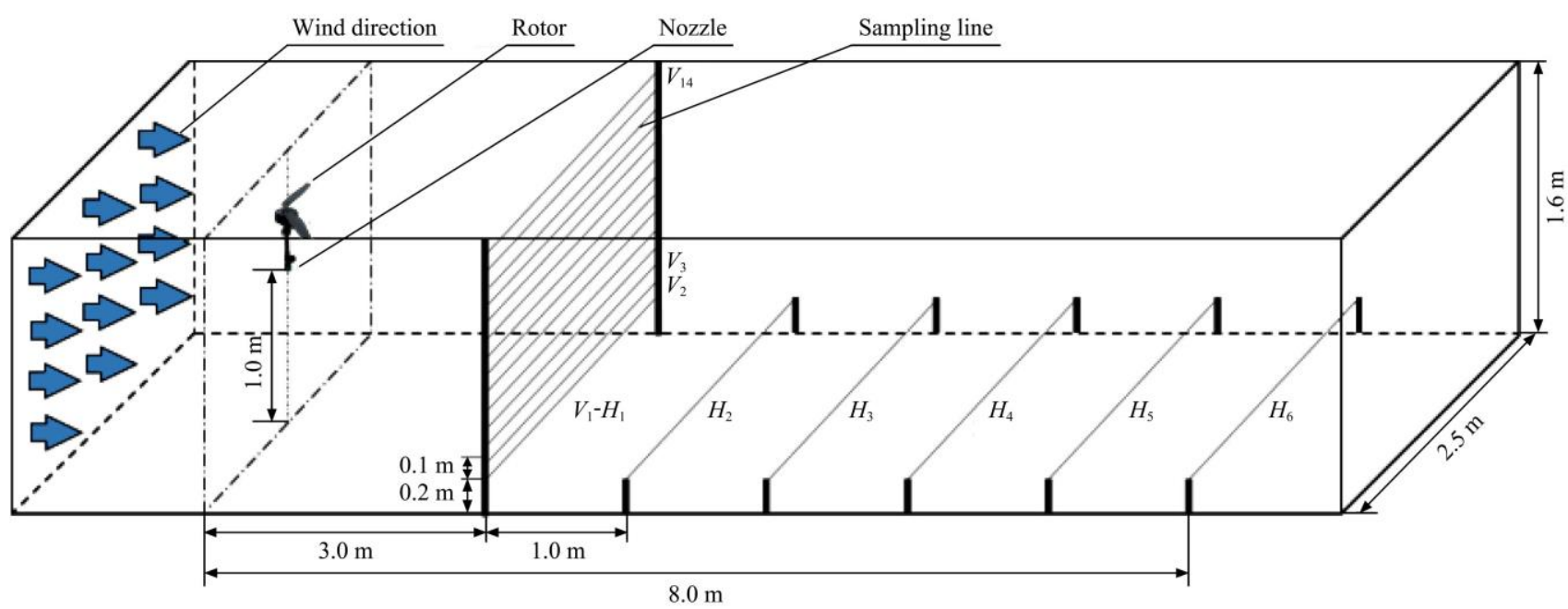

Figure 2 Wind tunnel measuring setup

Table 1 Experimental settings of wind tunnel measurements

\begin{tabular}{|c|c|c|c|c|c|c|}
\hline $\begin{array}{l}\text { Trial } \\
\text { No. }\end{array}$ & Nozzle model & $\begin{array}{c}\text { Spraying } \\
\text { time/s }\end{array}$ & $\begin{array}{c}\mathrm{T} \\
{ }^{\circ} \mathrm{C}\end{array}$ & $\begin{array}{l}\mathrm{RH} \\
1 \%\end{array}$ & $\begin{array}{c}\text { Wind speed } \\
\text { (flight speed) } \\
/ \mathrm{m} \cdot \mathrm{s}^{-1}\end{array}$ & Adjuvant \\
\hline 1 & $\begin{array}{l}\text { Lurmark } \\
\text { F110-03 }\end{array}$ & 5 & 20 & 80 & 5.0 & None \\
\hline 2 & ST 110-0067 & 5 & 20 & 80 & 5.0 & None \\
\hline 3 & ST 110-015 & 5 & 20 & 80 & 5.0 & None \\
\hline 4 & ST $110-02$ & 5 & 20 & 80 & 5.0 & None \\
\hline 5 & TR 80-0067 & 5 & 20 & 80 & 5.0 & None \\
\hline 6 & TR 80-01 & 5 & 20 & 80 & 5.0 & None \\
\hline 7 & IDK 90-0067 & 10 & 20 & 80 & 5.0 & None \\
\hline 8 & IDK 120-01 & 10 & 20 & 80 & 5.0 & None \\
\hline 9 & IDK 120-015 & 10 & 20 & 80 & 5.0 & None \\
\hline 10 & XR $110-01^{R 4}$ & 5 & 20 & 80 & 5.0 & None \\
\hline 11 & XR 110-03 & 5 & 20 & 80 & 5.0 & None \\
\hline 12 & TR 80-0067 & 5 & 20 & 80 & 2.0 & None \\
\hline 13 & XR 110-01 & 5 & 20 & 80 & 2.0 & None \\
\hline 14 & IDK 120-01 & 5 & 20 & 80 & 2.0 & None \\
\hline 15 & IDK 120-015 & 5 & 20 & 80 & 2.0 & None \\
\hline 16 & $\mathrm{XR} 110-01^{\mathrm{R} 3}$ & 5 & 30 & 40 & 5.0 & None \\
\hline 17 & XR 110-01 & 5 & 30 & 40 & 5.0 & DRS-60 \\
\hline 18 & XR 110-01 & 5 & 30 & 40 & 5.0 & Y-20079 \\
\hline 19 & XR 110-01 & 5 & 30 & 40 & 5.0 & G-611 \\
\hline 20 & XR 110-01 & 5 & 30 & 40 & 5.0 & MF \\
\hline 21 & XR 110-01 & 5 & 20 & 40 & 5.0 & None \\
\hline 22 & XR 110-01 & 5 & 30 & 60 & 5.0 & None \\
\hline 23 & XR 110-01 & 5 & 20 & 40 & 5.0 & MF \\
\hline 24 & XR 110-01 & 5 & 20 & 80 & 5.0 & $\mathrm{MF}$ \\
\hline 25 & XR 110-01 & 5 & 30 & 60 & 5.0 & MF \\
\hline
\end{tabular}

Note: Superscript R1, R2, R3 and R4 mean the marked trial is the reference spraying selected for data analysis of the corresponding study.

Ten hydraulic nozzles, including standard flat fan (FF) nozzles ST, hollow cone (HC) nozzles TR, air-inclusion (AI) flat nozzles IDK (Lechler GmbH, Metzingen, Germany) and extended range flat fan nozzles XR (TeeJet Technologies, USA), and a reference nozzle F110-03 (R1, Lurmark Limited, Longstanton, UK) were tested for both the nozzle type and size study at the wind speed of $5 \mathrm{~m} / \mathrm{s}$, the temperature of $20^{\circ} \mathrm{C}$ and the relative humidity of $80 \%$. Then 4 models of nozzles (TR 80-0067, XR 110-01, IDK 120-01 and IDK 120-015), which have been used in UAV aerial chemicals application, were selected in measurements at the lower wind speed of $2 \mathrm{~m} / \mathrm{s}$ for comparison between 2 different flight speeds and the reference spraying still Trial 1 (R2). Afterwards, 4 types of tank-mixed anti-drift adjuvants (DRS-60, Y-20079, G-611 and MF) were individually added into the sprayed fluid at their recommended concentration and the mixture was sprayed via XR 110-01 nozzle compared with a blank control test (R3) at a higher temperature of $30^{\circ} \mathrm{C}$ and a lower RH $40 \%$ (Table 2). In the end, 5 more trials were conducted at $20^{\circ} \mathrm{C}$ or $30^{\circ} \mathrm{C}$ and $40 \%-80 \%$ under the flight speed of $5.0 \mathrm{~m} / \mathrm{s}$ to compare the drift potential at 4 couples of weather conditions $\left(20^{\circ} \mathrm{C} \& 40 \%, 20^{\circ} \mathrm{C} \& 80 \%, 30^{\circ} \mathrm{C} \&\right.$ $40 \%$ and $30^{\circ} \mathrm{C} \& 60 \%$ ) when the spray adjuvant $\mathrm{MF}$ was applied or not, and the Trial 10 was selected as the reference spraying (R4). The spraying time was set at $5 \mathrm{~s}$ for FF nozzles and HC nozzles in wind tunnel tests, and because AI nozzles spray courser droplets than others, they sprayed for $10 \mathrm{~s}$ so as to collect enough droplets for determination.

Table 2 Tank-mixed adjuvants applied in wind tunnel measurements

\begin{tabular}{|c|c|c|c|}
\hline $\begin{array}{l}\text { Adjuvant } \\
\text { name }\end{array}$ & Main ingredient & Manufacturer & $\begin{array}{l}\text { Recommended } \\
\text { concentration }\end{array}$ \\
\hline $\begin{array}{c}\text { Silwet } \\
\text { DRS-60 }\end{array}$ & Organosilicon polymer & $\begin{array}{c}\text { Momentive Performance } \\
\text { Materials, Inc., USA }\end{array}$ & $0.5 \%$ \\
\hline Y-20079 & $\begin{array}{l}\text { Organosilicon surfactant } \\
\& \text { naturally derived } \\
\text { phospholipid emulsifiers }\end{array}$ & $\begin{array}{c}\text { Momentive Performance } \\
\text { Materials, Inc., USA }\end{array}$ & $0.5 \%$ \\
\hline MF & Methylated vegetable oil & $\begin{array}{l}\text { Beijing Grand AgroChem } \\
\text { Co. Ltd, China }\end{array}$ & $1.0 \%$ \\
\hline G-611 & Amphoteric polymer & $\begin{array}{l}\text { Shantou Dauni Research } \\
\text { Center, China }\end{array}$ & $0.33 \%$ \\
\hline
\end{tabular}

After each test, the collector lines were left to dry completely for $2 \mathrm{~min}$, then the dry lines were removed from the wind tunnel and washed with a known volume of deionized water in a U-tube fixed in an ultrasonic cleaner. The wash-off tracer solution from each collector and the diluent of the tank sample were measured with a fluorescence spectrophotometer (Model RF-1501, Shimadzu Corporation, Japan) and the droplets deposition per unit area at each downwind distance $\left(H_{i}\right)$ and at each height $\left(V_{i}\right)$ was calculated from the fluorescence.

\subsection{Droplets spectrum measurements}

Droplets spectrum measurements were conducted using a laser diffraction system (SprayTec, Malvern Panalytical Ltd, UK) in Centre for Chemicals Application Technology, China Agricultural University (CCAT, CAU) in 2018. Droplet whose size was in the range of $2-2000 \mu \mathrm{m}$ could be determined by the laser droplet size 
analyzer equipped with $750 \mathrm{~mm}$ lens at the data sampling frequency up to $2500 \mathrm{~Hz}$, providing stable and repeatable results. Before the test, the analyzer was turn on and warmed up for $30 \mathrm{~min}$, and the nozzle was fixed at a height of $50 \mathrm{~cm}$ above the laser analyzer vertically and at the midpoint of the laser beam transmitter and receiver lens. The SprayTec software was running and a sample test file was created and named after the test items. The background measurement was conducted for $5 \mathrm{~s}$ and then the droplet size spectrum measurements for $10 \mathrm{~s}$. The background test was performed to eliminate the interference of other particles in the air on the laser diffraction. The liquid pump was turned on to adjust the pressure to $0.3 \mathrm{MPa}$. The sampling process started after the pressure was stable, and finished when the measurement result page appeared, then the diameter below which smaller droplets constitute $50 \%$ of the total volume $\left(D_{v 50}\right)$, relative span $(R S)$ and the percentage of volume of droplets having a diameter smaller than $75 \mu \mathrm{m}\left(V_{75}\right)$ were saved for further analysis. The mean values of 5 replicates for each test were represented in tables and figures in results and discussion.

\subsection{Data analysis}

\subsubsection{Spray drift potential index}

For wind tunnel measurements of the quadrotor UAV's spray unit, the airborne spray drift potential was presented through the Drift Potential Index $(D I X)$ according to Herbst's determining method of spray drift potential ${ }^{[25,29]}$, which was calculated from the droplets deposition on the vertical collector lines. Integrating again over the drifting spray profile the volume flux $\dot{V}$ was calculated:

$$
\dot{V}=\int_{0}^{h_{N}} \int_{0}^{\infty} \dot{v}(y, z) \mathrm{d} y \mathrm{~d} z
$$

where, $\dot{V}$ is volume flux at any pint of the measuring plane.

Then, the relative drift potential volume was calculated by:

$$
V=\frac{\dot{V}}{\dot{V}_{N}}
$$

where, the $\dot{V}_{N}$ is nozzle output.

The characteristic height $h$ of the drift potential cloud was calculated by:

$$
h=\frac{\int_{0}^{h_{N}} \dot{v}(z) z d z}{\int_{0}^{h_{N}} \dot{v}(z) d z}
$$

Thus, the Drift Potential Index was defined as:

$$
D I X=\frac{h^{a} V^{b}}{h_{S t}^{a} V_{S t}^{b}} \times 100 \%
$$

where, $h_{S t}, V_{S t}$ are parameters from the reference spraying (Trial 1, 10 and 16); $\mathrm{a}$ and $\mathrm{b}$ are both empirical constants achieved from a regression analysis of wind tunnel and field measurements for different models of nozzles and they are respectively 0.88 and $0.78^{[29]}$.

\subsubsection{Spray drift potential}

For the measurements in the JKI wind tunnel, the horizontal spray drift potential $\left(D P_{H}\right)$ was expressed as the total sediment drift potential according to ISO $22856: 2008^{[15]}$ and Torrent et $\mathrm{al}^{[24]}$. The $D P_{H}$ was calculated by the following equations:

$$
D P_{H}=\sum_{i=1}^{6} H_{i}
$$

where, $D P_{H}$ represents the total sedimenting $D P, \% ; H_{i}$ is the sedimenting $D P$ at the horizontal collector tube $i(\%)$ on the basis of the following expressions:

$$
H_{i}=\left(\frac{v_{i} \cdot \frac{d}{D}}{q \cdot(t / 60)}\right) \times 100 \%
$$

Accordingly, the airborne drift potential $\left(V_{j}\right)$ at the vertical collector tube $j$ was calculated by:

$$
v_{j}=\left(\frac{v_{i} \cdot \frac{d}{D}}{q \cdot(t / 60)}\right) \times 100 \%
$$

where: $v_{(i / j)}$ is the deposition on the horizontal collector $i$ or the vertical tube $j, \mathrm{~L}$ (Equation (8)); $d$ is the distance between two adjacent collectors, $\mathrm{mm} ; D$ is the diameter of the collector tube, $\mathrm{mm}$; $q$ is the flow rate of nozzle, $\mathrm{L} / \mathrm{min} ; t$ is the spraying time, $\mathrm{h}$.

$$
v_{(i / j)}=\frac{\left(F_{\text {smpl }}-F_{b l k}\right) \times v_{d}}{F_{\text {spray }} \times R_{d}}
$$

where: $F_{\text {smpl }}$ is the fluorimeter reading of the sample; $F_{b l k}$ is the fluorimeter reading of the blanks (collector+ deionized water); $v_{d}$ is the dilution solution volume, $\mathrm{L} ; F_{\text {spray }}$ is the fluorimeter reading of the spray liquid diluent; $R_{d}$ is the dilution ratio of the spray liquid.

2.4.3 Spray drift potential reduction

The spray drift potential reduction percentage $(D P R P)$ in horizontal and vertical directions was calculated using the following expression:

$$
\begin{gathered}
D P R P_{V}=100 \%-D I X \\
D P R P_{H}=\left(1-\frac{D P_{H T}}{D P_{H S t}}\right) \times 100 \%
\end{gathered}
$$

where, $D P_{H T}$ is the horizontal drift potential of the treatment group, \%; $D P_{H S t}$ is the horizontal $D P$ of the reference trial.

\section{Results and discussion}

\subsection{Nozzle type and size study}

Vertical spray drift potential and horizontal spray drift potential resulting from measurments of different models of nozzles are shown in Figure 3. For all models of flat fan nozzle, hollow cone nozzle and air-inclusion flat nozzle, the vertical spray drift potential presented a similar pattern that with the decrease of the height of collector, the $D P$ increased significantly from the nozzle height $(100 \mathrm{~cm})$ and then decreased from $70 \mathrm{~cm}$ to 30 or $40 \mathrm{~cm}$, and increased again near the ground surface of the wind tunnel and in most cases there was a peak value at a height of $70 \mathrm{~cm}$. Similarly, the horizontal $D P$ also appeared a variation tendency with downwind distance that as the downwind distance increased horizontal $D P$ decreased firstly and then increased, and then decreased again, and the farthest downwind deposition distance of spray drift was greater than $8.0 \mathrm{~m}$ at a spraying height of $1.0 \mathrm{~m}$. It was analyzed that under the influence of the rotor's downwash airstream and the wind, part of spray droplets were blown immediately from the nozzle to the downwind direction, then dropped down and deposited at a further distance, so that the vertical $D P$ increased at first and the horizontal $D P$ went up from around $5 \mathrm{~m}$. Besides, different types of nozzles showed different levels of vertical and horizontal spray drift potential and their $D P$ values ranked in the order of FF nozzles, $\mathrm{HC}$ nozzles and $\mathrm{AI}$ nozzles. The degrees of significance of the variation trends from $V_{1}-V_{13}$ also varied for 3 types and the AI nozzles showed the weakest. Moreover, it could be found that for same type of nozzle, larger the nozzle size, higher the spray drift potential value. 

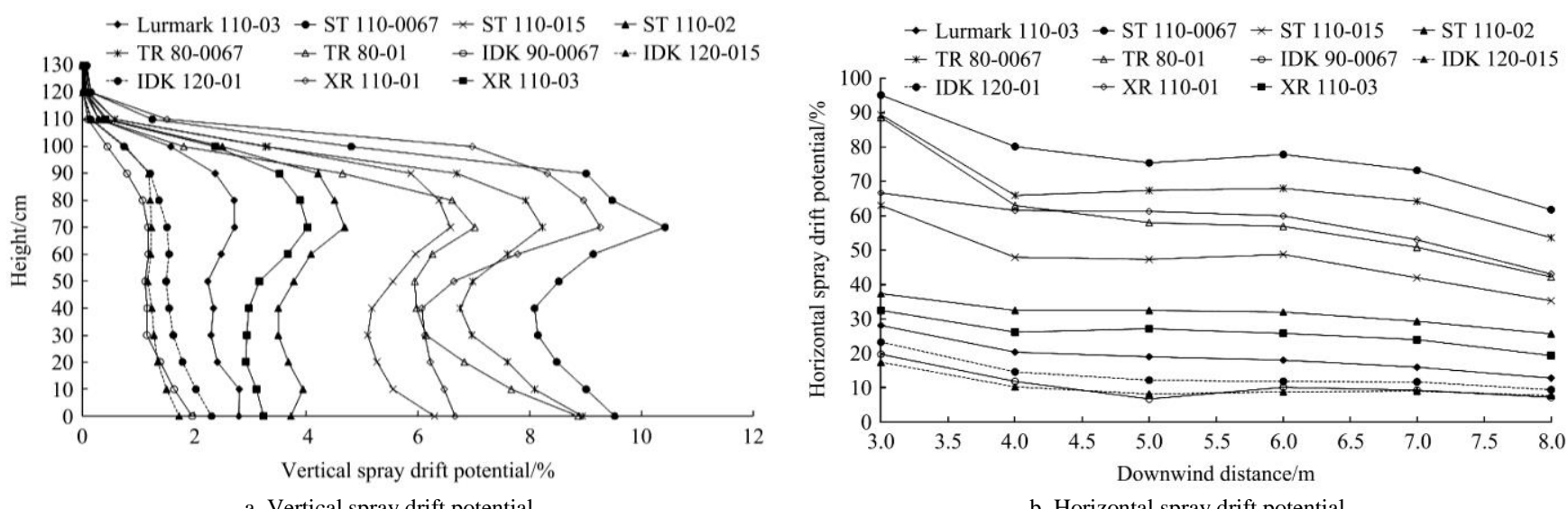

a. Vertical spray drift potential

b. Horizontal spray drift potential

Figure 3 Spray drift potential distribution of different models of nozzles

Table 3 and Figure 4 presented results of spray droplet spectrum and spray drift potential in nozzle type and size study. Their spray quality was defined by droplet spectra according to ASABE standard S572.1 $1^{[30]}$. For flat fan nozzles, with the increase of nozzle size from ISO 0067 to $03, D V_{50}$ rose from $118.9 \mu \mathrm{m}$ to $158.5 \mu \mathrm{m}$ and $V_{75}$ reduced $10 \%$ significantly, and meanwhile
$D P R P_{V}$ and $D P R P_{H}$ enhanced greatly correspondingly. Results of $\mathrm{HC}$ nozzles and AI nozzles also showed similar variation with FF nozzles except for IDK 90-0067. This minimum size ISO 0067 nozzle generated coarser droplets $\left(D V_{50}=487.5 \mu \mathrm{m}\right)$ than any other nozzles in this study and then had highest $D P R P_{V}$ and $D P R P_{H}$ values, meaning it has best anti-drift performance among these nozzles.

Table 3 Droplets spectrum, spray quality and spray drift potential of different nozzles tested in wind tunnel

\begin{tabular}{|c|c|c|c|c|c|c|c|c|}
\hline Nozzle type & Nozzle model & $D V_{50} / \mu \mathrm{m}$ & Spray quality & Relative span & $V_{75} / \%$ & $D I X / \%$ & $D P R P_{V} / \%$ & $D P R P_{H} / \%$ \\
\hline \multirow{4}{*}{ Flat fan nozzle } & ST $110-0067$ & $118.9 \pm 0.5 \mathrm{~h}$ & $\mathrm{VF}$ & $1.82 \pm 0.1 \mathrm{a}$ & $19.6 \pm 0.4 \mathrm{a}$ & $272.0 \pm 38.9$ & $-172.0 \pm 38.9$ & $-307.0 \pm 20.9$ \\
\hline & XR 110-01 & $122.6 \pm 0.7 \mathrm{~g}$ & VF & $1.36 \pm 0.1 \mathrm{~d}$ & $16.5 \pm 0.3 b$ & $259.4 \pm 20.7$ & $-159.4 \pm 20.7$ & $-203.4 \pm 10.5$ \\
\hline & ST $110-02$ & $142.7 \pm 0.7 \mathrm{e}$ & $\mathrm{F}$ & $1.42 \pm 0.0 \mathrm{~cd}$ & $12.0 \pm 0.2 \mathrm{~d}$ & $148.0 \pm 8.5$ & $-48.0 \pm 8.5$ & $-66.0 \pm 13.8$ \\
\hline & XR 110-03 & $158.5 \pm 0.7 \mathrm{~d}$ & $\mathrm{~F}$ & $1.63 \pm 0.0 \mathrm{~b}$ & $9.6 \pm 0.2 \mathrm{e}$ & $132.4 \pm 9.5$ & $-32.4 \pm 9.5$ & $-35.7 \pm 8.6$ \\
\hline \multirow{2}{*}{ Hollow cone nozzle } & TR 80-0067 & $114.9 \pm 0.7 \mathrm{i}$ & $\mathrm{VF}$ & $1.07 \pm 0.0 \mathrm{e}$ & $16.1 \pm 0.7 b$ & $225.0 \pm 26.4$ & $-125.0 \pm 26.4$ & $-258.7 \pm 7.8$ \\
\hline & TR 80-01 & $123.5 \pm 0.6 \mathrm{~g}$ & $\mathrm{VF}$ & $1.14 \pm 0.0 \mathrm{e}$ & $14.2 \pm 0.8 \mathrm{c}$ & $189.0 \pm 30.1$ & $-89.0 \pm 30.1$ & $-215.8 \pm 4.0$ \\
\hline \multirow{3}{*}{ Air-inclusion nozzle } & IDK 90-0067 & $487.5 \pm 1.5 \mathrm{a}$ & $\mathrm{XC}$ & $1.64 \pm 0.0 \mathrm{~b}$ & $0.8 \pm 0.0 \mathrm{~g}$ & $50.0 \pm 11.6$ & $50.0 \pm 11.6$ & $43.5 \pm 4.8$ \\
\hline & IDK 120-01 & $274.3 \pm 1.6 \mathrm{c}$ & M & $1.72 \pm 0.0 \mathrm{ab}$ & $2.6 \pm 0.1 \mathrm{f}$ & $105.2 \pm 13.9$ & $-5.2 \pm 13.9$ & $27.5 \pm 9.2$ \\
\hline & IDK 120-015 & $312.6 \pm 1.8 \mathrm{~b}$ & $\mathrm{C}$ & $1.70 \pm 0.0 \mathrm{~b}$ & $1.8 \pm 0.1 \mathrm{f}$ & $57.6 \pm 7.6$ & $42.4 \pm 7.6$ & $46.6 \pm 5.8$ \\
\hline
\end{tabular}

Note: Spray quality classification: VF-very fine, F-fine, M-medium, C-coarse, VC-very coarse; the droplet spectrum and spray drift results were expressed as 'mean \pm standard error'; Different letters indicate significant differences between nozzles (Duncan test, $p<0.05$ ).

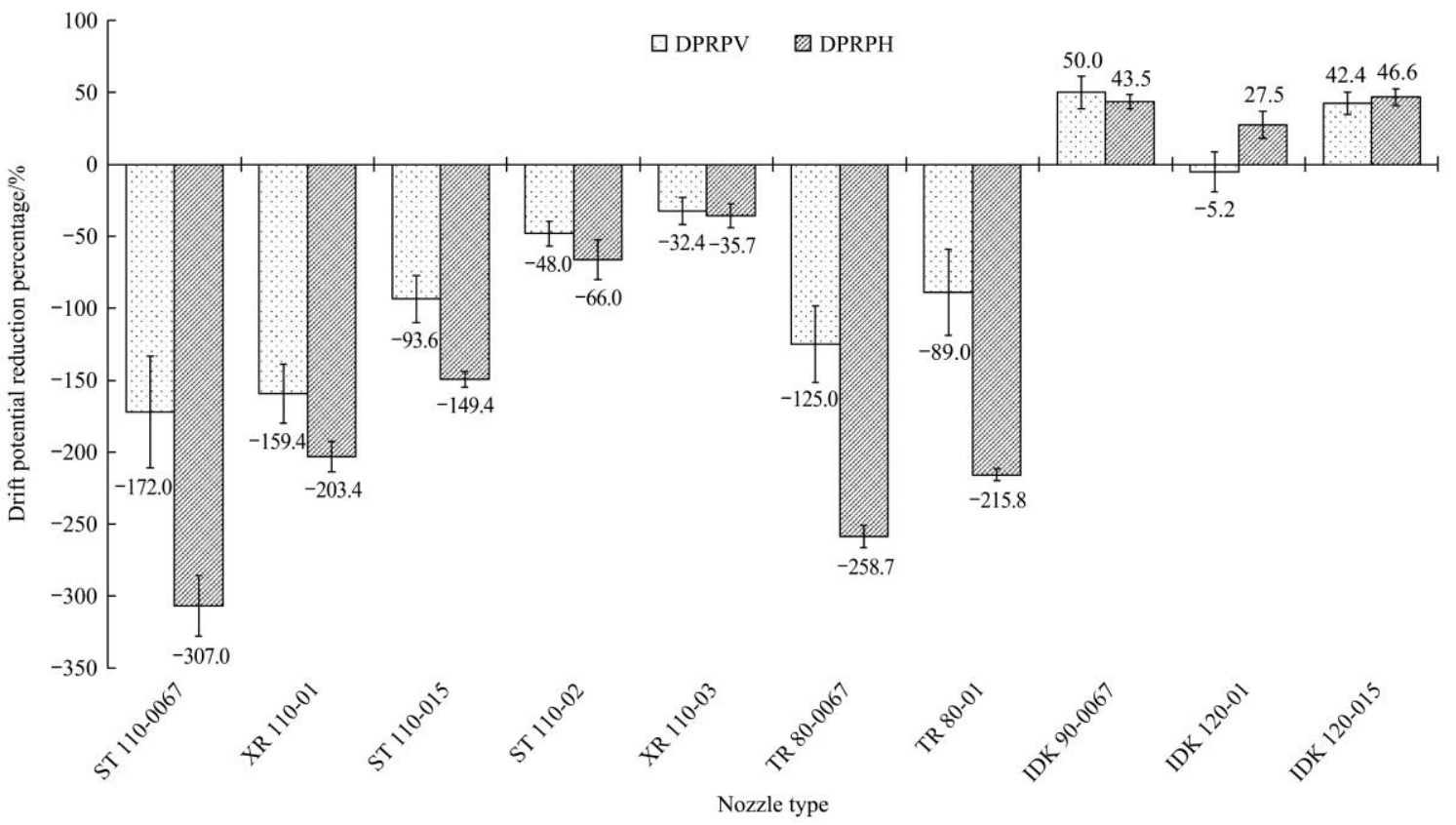

Figure 4 Comparison of spray drift potential reduction percentage of different models of nozzles

For tests of all 3 types of nozzles, there was no significant difference between the variation tendencies of the $D P R P_{V}$ value and $D P R P_{H}$. It was found that the $D P R P_{V}$ and $D P R P_{H}$ values of FF nozzles and $\mathrm{HC}$ nozzles were all negative $(-32.4 \%$ to $-307.0 \%)$ 
and turned to positive (27.5\% to 50.0\%) when using AI nozzles, and ranked in the order of FF nozzle, HC nozzle and AI nozzle under the same size, which indicated the anti-drift performance was ranked in the order of $\mathrm{AI}$ nozzle, $\mathrm{HC}$ nozzle and FF nozzle, and only AI nozzles had better anti-drift performance in the wind tunnel compared with the reference nozzle. In spite of the $D V_{50}$ of the FF and HC nozzle didn't show much difference, the $V_{75}$ and the relative span of the $\mathrm{HC}$ nozzle were statistically lower than the FF nozzle, which meant the $\mathrm{HC}$ nozzle sprayed less fine droplets with better uniformity in size, so with the same size the HC nozzle showed better anti-drift performance than the FF nozzle.

In addition, Figure 4 showed clearly that the AI nozzles had higher DPRP values than others and could reduce approximately $30 \%-50 \%$ of spray drift effectively, meanwhile the DPRP values promoted significantly with the ISO nozzle size increase to 02 and 03 for FF nozzles. Considering that the suitable droplet size range for UAV is within 100-300 $\mu \mathrm{m}$ according to the biological optimum droplet size (BODS) and requirements for ULV/LV aerial chemicals application $^{[31]}$, the recommended nozzles for UAV aerial spraying were flat fan 02 nozzle and air-inclusion 01 nozzle compared with other nozzles tested in this study.

Based on the above analysis, a correlation analysis between the droplet spectrum results and the DPRP results was conducted and its results were presented in Table 4. As shown in the Table 4, a highly significant positive correlation was found between $D P R P_{V}$ and $D V_{50}$, and $D P R P_{H}$ and $D V_{50}(p<0.01, r>0)$, while a highly significant negative correlation was found between $D P R P_{V}$ and $V_{75}$, and $D P R P_{H}$ and $V_{75}(p<0.01, r<0)$, confirming the droplets size and the ratio of fine droplets have significant influence on spray drift potential, and the nozzle type and size affected the $D P$ by changing the droplets size and the ratio of fine droplets. Thus, a linear regression analysis with $D P R P_{V} / D P R P_{H}$ as the dependent variable and $D V_{50}$ and $V_{75}$ as independent variables was conducted and the regression models are showed as the equation (11) and (12), where the coefficients of determination $\left(R^{2}\right)$ were respectively 0.934 and 0.925 , indicating a good fit of the regression. In the study on spray drift for single-rotor UAV sprayers in wheat field in 2015 and $2016^{[11,32]}$, it was found that $D V_{0.5}$ and $V_{75}$ had very significant effects on spray drift percentage $(p<0.01)$ and drift rate increased as $V_{75}$ increased and as $D V_{0.5}$ of droplets decreased. These results of this work further support the idea of the previous field tests.

$$
\begin{array}{cc}
D P R P_{V}=-0.054 D V_{50}-11.994 V_{75}+76.768 & R^{2}=0.934 \\
D P R P_{H}=-0.325 D V_{50}-23.707 V_{75}+208.209 & R^{2}=0.925
\end{array}
$$

In conclusion, at the given environmental parameters, the larger the nozzle size, the better anti-drift performance for the FF nozzles, HC nozzles and AI nozzles; for the same nozzle size, air-inclusion nozzles generally had better anti-drift performance followed by the hollow cone and then the flat fan nozzles; nozzle type and nozzle size had an impact on the spray drift potential obviously and the effect was achieved by affecting the droplet size and the ratio of fine droplets of the spray cloud.

Table 4 Correlation analysis between the spray droplet

\begin{tabular}{|c|c|c|c|}
\hline & & $D P R P_{V}$ & $D P R P_{H}$ \\
\hline \multirow{2}{*}{$D V_{50}$} & Significance, $P$ & $0.003 * *$ & $0.009 * *$ \\
\hline & Correlation coefficient, $r$ & 0.834 & 0.774 \\
\hline \multirow{2}{*}{ Relative span } & Significance, $P$ & 0.379 & 0.167 \\
\hline & Correlation coefficient, $r$ & 0.280 & 0.473 \\
\hline \multirow{2}{*}{$V_{75}$} & Significance, $P$ & $<0.001 * *$ & $<0.001 * *$ \\
\hline & Correlation coefficient, $r$ & -0.966 & -0.951 \\
\hline
\end{tabular}
spectrum results and the spray drift results

\subsection{Flight speed study}

Figure 5 showed the spray drift potential distribution at the vertical plane of 4 selected nozzles at 2 flight speeds. From the distribution of the vertical spray drift, almost all the $D P$ values of the 4 trials at the wind speed of $2.0 \mathrm{~m} / \mathrm{s}$ were lower than $1.0 \%$ and a significant reduction of spray drift potential was found compared with those at $5.0 \mathrm{~m} / \mathrm{s}$. As the wind speed decreased to $2.0 \mathrm{~m} / \mathrm{s}$, from top to bottom, there was no obvious change observed of the $D P$ on the vertical collector lines except a small increase on several collector lines near the ground for the XR and the TR nozzle, and even drift droplets could be hardly detected for those two models of AI nozzles $\left(H_{1}-H_{13}\right.$ values were not more than $\left.0.1 \%\right)$. Furthermore, the variation trend of first increasing, then decreasing and increasing again for the vertical $D P$ from nozzle to the ground disappeared. The comparison of their vertical and horizontal spray drift potential reduction percentage values was presented in Figure 6. Comparing the results obtained under two wind speeds, it was seen that when the drone's flight speed decreased, both the vertical and the horizontal spray drift reduction rate of the FF nozzle and the HC nozzle promoted by more than $200 \%$, and that of the AI nozzle could promote by at least $50 \%$ up to $90 \%$, which showed no matter the $D P R P_{V}$ or the $D P R P_{H}$ would be greatly improved, reducing the risk of droplets drift during UAV chemical spraying operations.

- IDK 120-015@2 m/s •-TR 80-0067@2 m/s —XR 110-01@2 m/s .- IDK 120-01@2 m/s

-IDK 120-015@5 m/s - -TR 80-0067@5 m/s —XR 110-01@5 m/s - IDK 120-01@5 m/s

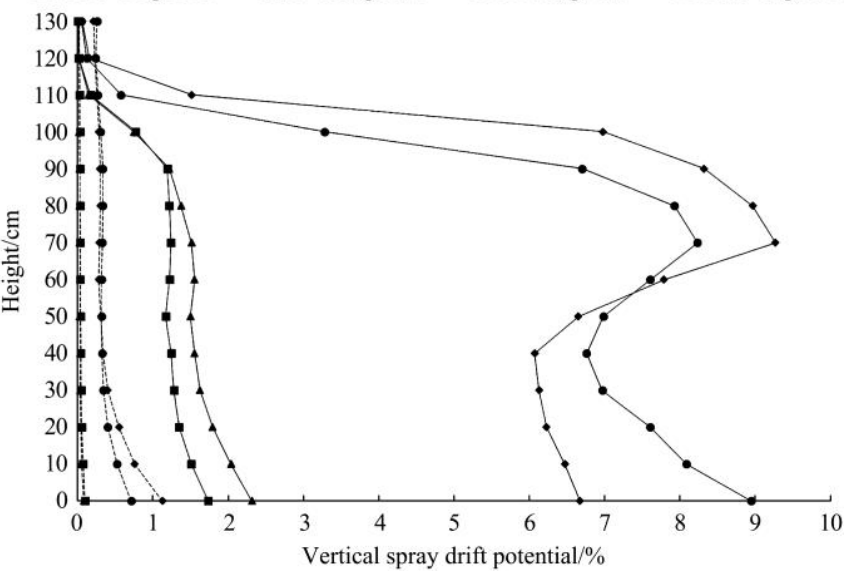

Figure 5 Vertical spray drift potential distribution of 4 selected nozzles at 2 wind speeds

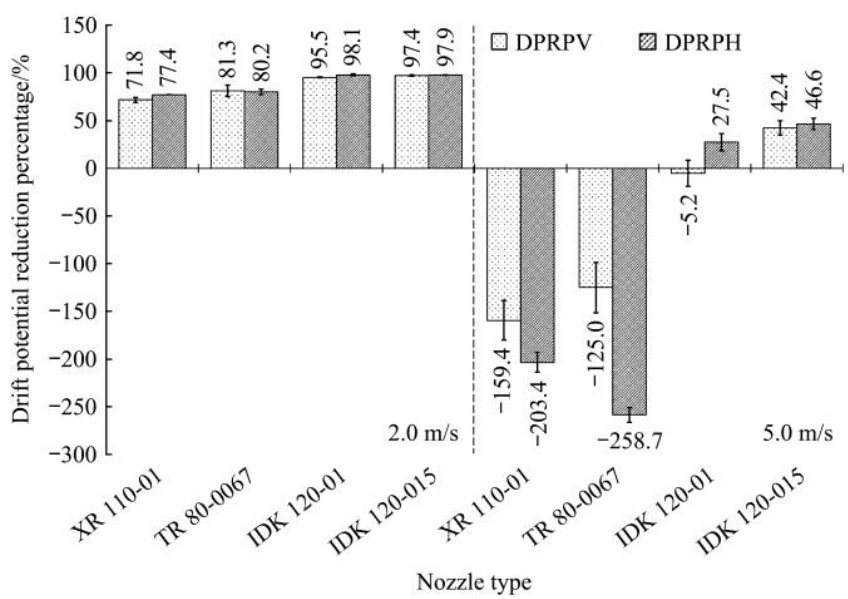

Figure 6 Comparison of spray drift potential reduction percentage of 4 selected models of nozzles at 2 flight speeds

In summary, all these facts above indicated that the flight speed had a significant effect on the spray drift characteristics of 
the UAV sprayer, and reducing the flight speed could increase the spray drift potential effectively. It is analyzed that when the drone fly too fast $(\geq 5 \mathrm{~m} / \mathrm{s})$, the direction of the downwash airstream of the rotor would change from vertical downward to obliquely downward under the influence of the relative moving external wind, which weakened the pressing effect on sprayed droplets, and the horizontal velocity of the downwash airflow instead increased the external wind speed in the reverse flight direction, aggravating the spray drift toward the rear of the fuselage. That was why there was a peak of the $D P$ value appeared at the height of $70-80 \mathrm{~cm}$. In contrast, as the flying speed was lower than $2 \mathrm{~m} / \mathrm{s}$, without the external crosswind, the downward airflow could effectively assist sprayed droplets to fall down and promote the downward movement and the deposition on the target crop, which caused a great reduction of the spray drift potential due to the external wind. Similarly, it could be inferred that if the unmanned aircraft worked under the natural crosswind, the rotor's airflow would be further dispersed, and thereby the down-pressing effect on the droplets cloud would be further weakened, as well. In accordance with the present results and analysis, author's previous study of downwash airflow and spray deposition ${ }^{[33]}$ have demonstrated that with the increase of the flight speed, the downwash airflow field decreased obviously and its promotion effect on droplets deposition disappeared when speed reached $6.0 \mathrm{~m} / \mathrm{s}$.

\subsection{Spray adjuvant and meteorological condition study}

Figure 7 showed the vertical spray drift potential distribution at each height of 4 types of adjuvant treatments and a blank control and Figure 8 showed the comparison of the $D P R P_{V}$ and $D P R P_{H}$ values of 4 selected adjuvant solutions. It was found that under a high temperature $\left(30^{\circ} \mathrm{C}\right)$ and low humidity $(40 \%)$ conditions, the spraying solutions of the 3 adjuvants DRS-60, MF and Y-20079 prepared according to the recommended concentration could reduce the spray drift in different degrees, and DRS-60 had a better drift reduction effect than the others and its vertical and horizontal DPRP reached $33.2 \%$ and $45.8 \%$, respectively. The order of the strength of the 3 types of adjuvants with anti-drift function was DRS-60>MF>Y-20079. DRS-60 reflected a good anti-drift performance in the research of Wang et al. ${ }^{[11]}$ and they also found that adjuvants DRS-60 have better drift reduction ability than others in wheat field tests. Compared with the blank control, except for the height of $80 \mathrm{~cm}$ and $90 \mathrm{~cm}$, the droplets deposition of the adjuvant G-611 in vertical collector lines increased, showing this adjuvant could not only have no anti-drift effect but also increased the risk of spray drift $(D P R P<0)$.

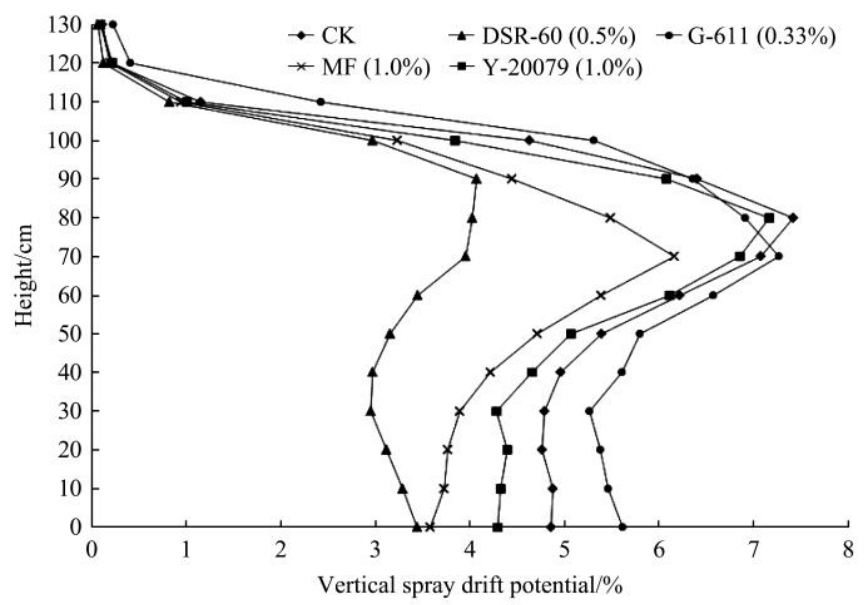

Figure 7 Vertical spray drift potential distribution of 4 selected adjuvants and water

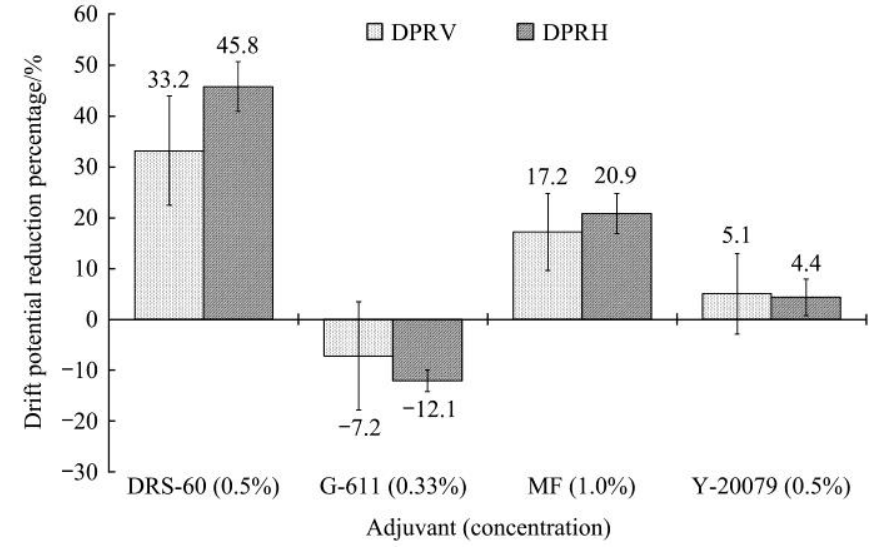

Figure 8 Comparison of spray drift potential reduction percentage of 4 selected adjuvants

The drift potential reduction percentage values of the $1.0 \% \mathrm{MF}$ solution and water under 4 different couples of meteorological conditions were presented in Figure 9 and the blank control at $20^{\circ} \mathrm{C}$ temperature and $80 \% \mathrm{RH}$ (Trial 10) were both 0 because it was the reference spraying for this part of study. For the same spray liquid, the drift potential values measured under different meteorological conditions were slightly different. The $D P R P_{V}$ and $D P R P_{H}$ values of the blank control group except for the reference trial were within the range of $18.2 \%-28.7 \%$, while those of adjuvant treatments were in the range of $30.2 \%-35.7 \%$ except the $D P R P_{V}$ and $D P R P_{H}$ were respectively $24.6 \%$ and $21.5 \%$ for the $20^{\circ} \mathrm{C} \& 80 \%$ group. Under the 4 couples of temperature and humidity conditions, the DPRP values in both vertical and horizontal directions would be increased in different degrees after the adjuvant MF was applied, contributing to the reduction of the spray drift risk. Moreover, the most obvious effect of adding adjuvant on spray drift reduction was found for the measurements under a lower temperature and higher humidity condition (For the $20^{\circ} \mathrm{C} \& 80 \%$ group $D P R P_{V}$ and $D P R P_{H}$ were both increased by more than $20 \%$ ) and a higher temperature and lower humidity conditions (For the $30^{\circ} \mathrm{C} \& 40 \%$ group $D P R P_{V}$ and $D P R P_{H}$ were increased by $14.0 \%$ and $16.9 \%$, respectively).

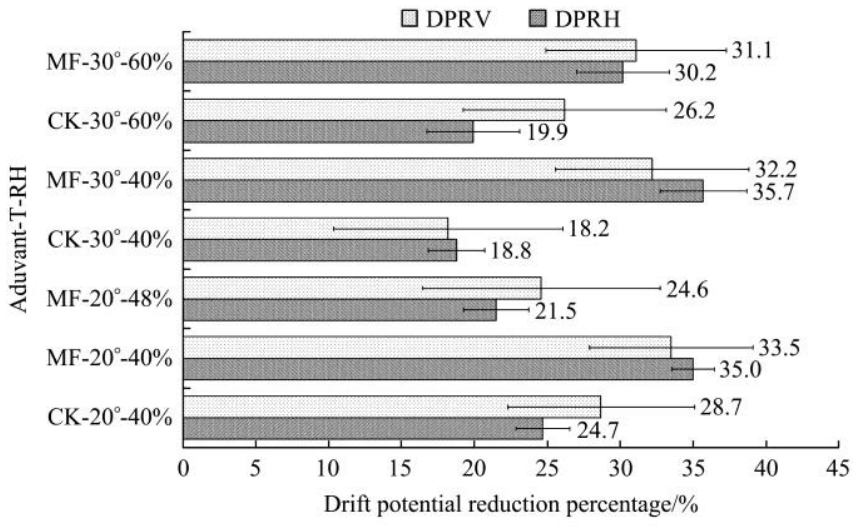

Figure 9 Comparison of spray drift potential reduction percentage of the $1.0 \%$ MF solution and water under 4 couples of meteorological condition

In general, adding spray adjuvants into the spray solution had a significant effect on the spray drift level, but the results showed different drift reduction for different types of adjuvants; regarding UAV's chemicals application work in the field, especially under the high temperature and low humidity condition, using the adjuvant DRS-60 solution at a concentration of $0.5 \%$ or the MF solution at a concentration of $1.0 \%$ as spray liquid could reduce the 
spray drift potential, contributing to improve the effective utilization of PPP.

\section{Conclusions}

Twenty-five treatments of wind tunnel measurements and droplets spectrum tests of 10 models of nozzles were conducted to study the effect of nozzle type and size, flight speed, adjuvant and meteorological parameter on spray drift characteristics of UAV chemicals application. A spray unit was innovatively installed in wind tunnel and spray drift potential results under the rotor's downwash airflow and the external wind were obtained for the first time. The main conclusions were obtained as follows:

(1) The larger the nozzle size, the better anti-drift performance; for the same size, air-inclusion nozzle generally had better anti-drift performance followed by the hollow cone and then the flat fan nozzle; both nozzle type and size had an impact on the spray drift potential obviously by affecting the droplet size and the ratio of fine droplets of the spray cloud, and the regression linear models between $D P R P_{V} / D P R P_{H}$ and $D V_{50}, V_{75}$ were established $\left(R^{2}=\right.$ $0.934 / 0.925)$.

(2) The flight speed had a significant effect on the spray drift characteristics for UAV aerial application, and reducing the flight speed could increase the spray drift potential effectively. If the drone flew too fast, the direction of the rotor's downwash airflow would change under the influence of the relative moving external wind and weaken the pressing effect on droplets, aggravating the risk of spray drift.

(3) Adding spray adjuvants into the spray solution could influence the spray drift level under all 4 couples of meteorological parameters, and the drift reduction effect for the 3 types of adjuvants with anti-drift performance ranked in the order of DRS-60>MF>Y-20079.

Therefore, in order to reduce the spray drift effectively for UAV pesticides applications, the following recommendations were proposed: use AI nozzles IDK 120-01/015 to replace FF and XR nozzles; reduce the flying speed to ensure the pressing effect of the rotor's downwash airflow on droplets; apply appropriate spray adjuvants into the spray solution, such as Silwet DRS-60 and MF. In this study, only one spray unit of the UAV was arranged for preliminary spray drift tests due to the limitation of the wind tunnel width and the influence among the rotors was not considered. It is planned to introduce the entire multi-rotor UAV into the wind tunnel test to further investigate the interaction between different rotors and their impacts on spray deposition and drift behaviors, which would help make the indoor measurement conditions much closer to the real operation scenario and enhance the credibility of the wind tunnel test results of UAV sprayers.

\section{Acknowledgements}

This study was supported by Sino-German Cooperation Project (31761133019) supported by National Natural Science Foundation of China, National Key R\&D Program of China (2017YFD0200304) and China Postdoctoral Science Foundation Funded Project (2019M650907). The authors would like to thank Mr. Sven Nolten and other staff of Institute for Application Techniques in Plant Protection, JKI and all staff of CCAT, China Agricultural University for their contributions to this work.

\section{[References]}

[1] He X K, Bonds J, Herbst A, Langenakens J. Recent development of unmanned aerial vehicle for plant protection in East Asia. Int J Agric \& Biol Eng, 2017; 10(3): 18-30.

[2] Lan Y, Chen S, Deng J, Zhou Z, Ouyang F. Development situation and problem analysis of plant protection unmanned aerial vehicle in China. Journal of South China Agricultural University, 2019; 40(5): 217-225. (in Chinese)

[3] Huang Y, Hoffmann W C, Lan Y, Wu W, Fritz B K. Development of a spray system for an unmanned aerial vehicle platform. Applied Engineering in Agriculture, 2009; 25(6): 803-809.

[4] He X, Liu Y, Song J, Zeng A, Zhang J. Small unmanned aircraft application techniques and their impacts for chemical control in Asian rice fields. Aspects of Applied Biology, 2014; 122: 33-45.

[5] Lan Y, Chen S. Current status and trends of plant protection UAV and its spraying technology in China. International Journal of Precision Agricultural Aviation, 2018, 1(1): 1-9.

[6] Yang S, Yang X, Mo J. The application of unmanned aircraft systems to plant protection in China. Precision Agriculture, 2018; 19: 278-292.

[7] He X. Rapid development of unmanned aerial vehicles (UAV) for plant protection and application technology in China. Outlooks on Pest Management, 2018, 29(4): 162-167.

[8] Wang C L, Song J L, He X K, Wang Z C, Wang S L, Meng Y H. Effect of flight parameters on distribution characteristics of pesticide spraying droplets deposition of plant-protection unmanned aerial vehicle. Transactions of the CSAE, 2017; 33(23): 109-116. (in Chinese)

[9] He X K. Brief analysis on the research, development and application of plant protection UAV in China. Pesticide Science and Administration, 2018; 39(9): 10-17. (in Chinese)

[10] ISO 22866. Equipment for crop protection - Methods for field measurement of spray drift. ISO International Standard, 2005.

[11] Wang X N, He X K, Song J L, Wang Z C, Wang C L, Wang S L, et al Drift potential of UAV with adjuvants in aerial applications. Int J Agric \& Biol Eng, 2018; 11(5): 54-58.

[12] Wang J, Lan Y B, Zhang H H, Zhang Y L, Wen S, Yao W X, Deng J Drift and deposition of pesticide applied by UAV on pineapple plants under different meteorological conditions. Int J Agric \& Biol Eng, 2018; 11(6): 5-12.

[13] Wang J, Lan Y, Wen S, Hewitt A J, Yao W, Chen P. Meteorological and flight altitude effects on deposition, penetration, and drift in pineapple aerial spraying. Asia-Pacific Journal of Chemical Engineering, 2020; 15(1): e2382.

[14] Herbst A, Bonds J, Wang Z C, Zeng A J, He X K, Goff P. The influence of unmanned agricultural aircraft s ystem design on spray drift. Journal für Kulturpflanzen, 2020; 72(1): 1-11.

[15] ISO 22856. Equipment for crop protection — Methods for the laboratory measurement of spray drift - Wind tunnels. ISO International Standard, 2008.

[16] ISO 22401. Equipment for crop protection - Method for measurement of potential spray drift from horizontal boom sprayers by the use of a test bench. ISO International Standard, 2015.

[17] Douzals J-P, Tinet C, Goddard R. Use of a flexible drop counter for a better comparability of potential spray drift measurement protocols in wind tunnels. Aspects of Applied Biology International Advances in Pesticide Application, 2018; 137(1): 277-284.

[18] ISO 25358. Crop protection equipment-droplet-size spectra from atomizers-measurement and classification. ISO International Standard, 2018.

[19] Van de Zande J C, Holterman H J, Wenneker M. Nozzle classification for drift reduction in orchard spraying; identification of drift reduction class threshold nozzles. Agricultural Engineering International: the CIGR Ejournal, 2008; 5: 253-260.

[20] Sousa Alves G, Kruger G R, da Cunha J P A R, Vieira B C, Henry R S, Obradovic A, et al. Spray drift from dicamba and glyphosate applications in a wind tunnel. Weed Technology, 2017; 31(3): 387-395.

[21] Brusselman E, Van Driessen K, Steurbaut W, Gabriels D, Cornelis W, Nuyttens D, et al. Wind tunnel evaluation of several tracer and collection techniques for the measurement of spray drift. Communications in agricultural and applied biological sciences, 2004; 69(4): 829-836.

[22] Torrent X, Garcerá C, Moltó E, Chueca P, Abad R, Grafulla C, et al. Comparison between standard and drift reducing nozzles for pesticide application in citrus: Part I. Effects on wind tunnel and field spray drift. Crop Protection, 2017; 96: 130-143

[23] Nuyttens D, Taylor W A, De Schampheleire M, Verboven P, Dekeyser D. Influence of nozzle type and size on drift potential by means of different 
wind tunnel evaluation methods. Biosystems Engineering, 2009; 103(3): 271-280

[24] Torrent X, Gregorio E, Douzals J P, Tinet C, Rosell-Polo J R, Planas S. Assessment of spray drift potential reduction for hollow-cone nozzles: Part 1. Classification using indirect methods. Science of the Total Environment, 2019; 692: 1322-1333.

[25] Herbst A. A method to determine spray drift potential from nozzles and its link to buffer zone restrictions. ASAE Annual International Meeting. Sacramento, California, USA: 01-1047, 2001

[26] Zhang W J, He X K, Song J L, Wang C L, Herbst A. Effect of adjuvant S240 on atomization of water dispersible granule and emulsion solution. Transactions of the CSAE, 2014; 30(11): 61-67. (in Chinese)

[27] Wang X, He X K, Herbst A, Langenakens J, Zheng J, Li Y. Development and performance test of spray drift test system for sprayer with bar. Transactions of the CSAE, 2014; 30(18): 55-62. (in Chinese)

[28] Blocken B. 50 years of computational wind engineering: past, present and future. Journal of Wind Engineering and Industrial Aerodynamics, 2014; 129: 69-102.

[29] Helck C, Herbst A. Drift potential index-a new parameter for the evaluation of agricultural nozzles concerning their drift potential. Nachrichtenbl. Deut. Pflanzenschutzd, 1998; 50(9): 225-232.

[30] ASABE S572.1. Spray nozzle classification by droplet spectra. ASABE Standard, 2009.

[31] Himel C M, Moore A D. Spray droplet size in the control of spruce budworm, boll weevil, bollworm, and cabbage looper. Journal of Economic Entomology, 1969; 62(4): 916-919.

[32] Wang X N, He X K, Wang C L, Wang Z C, Li L L, Wang S L, et al. Spray drift characteristics of fuel powered single-rotor UAV for plant protection. Transactions of the CSAE, 2017; 33(1): 117-123. (in Chinese)

[33] Wang C L. Droplet atomization and deposition distribution characteristics of unmanned aerial vehicle chemical application, Beijing: China Agricultural University, 2018. (in Chinese) 